\title{
Roles of Platelet-Activating Factor and Thromboxane in Group B Streptococcus-Induced Pulmonary Hypertension in Piglets
}

\author{
JOAQUIM M. B. PINHEIRO, BRUCE R. PITT, AND C. NORMAN GILLIS \\ Departments of Pediatrics and Anesthesiology, Yale University School of Medicine, \\ New Haven, Connecticut 06510
}

\begin{abstract}
Platelet-activating factor causes pulmonary hypertension, shock, hypoxemia, neutropenia, and increased pulmonary vascular permeability; some of its effects are due to thromboxane $A_{2}$ release. Evidence for a possible role of these mediators in the genesis of group B Streptococcus (GBS)-induced pulmonary hypertension was sought using specific receptor antagonists for PAF and thromboxane $\mathrm{A}_{2}\left(\mathrm{TxA}_{2}\right)$ in anesthetized, ventilated piglets ( $\leq 12 \mathrm{~d}$ of age; $n=22$ ). Infusion of $1 \times 10^{8} \mathrm{GBS} / \mathrm{kg} / \mathrm{min}$ for one hour resulted in a sustained and significant increase in pulmonary artery pressure $\left(\mathrm{P}_{\mathrm{PA}_{\mathrm{A}}}\right)$ from $17 \pm 1$ to $35 \pm 3$ torr. Pretreatment with the $\mathrm{TxA}_{2}$ antagonist SQ 29548 $(0.75 \mathrm{mg} / \mathrm{kg}$ intravenous), completely inhibited the effect of GBS on $\mathrm{P}_{\mathrm{PA}}$. Pretreatment with either platelet-activating factor antagonists SRI $63072(3 \mathrm{mg} / \mathrm{kg}$ intravenous) or SRI $63441(1 \mathrm{mg} / \mathrm{kg})$ did not affect the pulmonary hypertension due to GBS infusion. GBS-induced pulmonary hypertension could be reversed by SQ 29548; SRI 63072 did not affect $P_{P A}$ when administered to pigs with GBS-induced elevation in $\mathbf{P}_{\mathrm{PA}}$. Inasmuch as prevention and reversal of GBS-induced pulmonary hypertension are accomplished with the $\mathrm{TXA}_{2}$ antagonist but not with PAF antagonists, these data suggest that $T \times A_{2}$, rather than PAF, is responsible for the early pulmonary hypertension in this model of neonatal GBS sepsis. Therefore, $\operatorname{TxA}_{2}$ antagonists may be clinically useful in treating pulmonary hypertension related to GBS sepsis. (Pediatr Res 26: 420-424, 1989)
\end{abstract}

\section{Abbreviations}

GBS, group B Streptococcus

5HETE, 5-hydroxyeicosatetraenoic acid

PAF, platelet-activating factor

$P_{P_{A}}$, pulmonary artery pressure

$\mathrm{TxA}_{2}$, thromboxane $\mathrm{A}_{2}$

In the human neonate, GBS septicemia is associated with pulmonary hypertension, shock, hypoxemia, granulocytopenia, and a high mortality rate, despite antibiotic therapy (1). The pathophysiology of the clinical syndrome has been reproduced in animal models by infusion of live or heat-killed GBS or its endotoxins (2-4). Inflammatory mediators implicated in the early phase responses to endotoxemia (pulmonary hypertension

Received March 14, 1988; accepted June 13, 1989. Correspondence Dr. Bruce R. Pitt, Department of Pharmacology, University of Pittsburgh School of Medicine, Pittsburgh, PA 15261

Supported in part by NIH Grant HL-32154 and HL-13315, as well as postdoctoral training support Grant HL-07410. This work was done during the tenure of B.R.P. as an Established Investigator of the American Heart Assocation. and hypoxemia) include cyclooxygenase products [TxA $(5-9)]$, and leukotrienes (11). Lipoxygenase products [5-HETE, 12HETE, leukotrienes $\mathrm{C}_{4}$ and $\mathrm{D}_{4}(10)$ ] may also play a role in the pathogenesis of the late phase pulmonary vascular injury and increased permeability. TxA 2 and leukocytes appear to be important mediators of the pulmonary dysfunction induced by GBS toxin in lambs (33).

PAF is an autocoid phospholipid mediator with a basic structure of 1-O-alkyl-2-acetyl-sn-glycero-3-phosphorylcholine. Its cellular sources include endothelial cells, platelets, neutrophils, mast cells, and macrophages; its release can be elicited by multiple inflammatory stimuli $(12,13)$. Among its many biologic effects is the ability to aggregate platelets and neutrophils (12, 14), and to cause activation of cyclooxygenase and lipoxygenase pathways $(12,23,35)$. In whole animals, PAF is capable of inducing pulmonary hypertension, shock, hypoxemia, neutropenia $(12,13)$, and increased pulmonary vascular and epithelial permeability $(14-16,38)$. In newborn piglets, PAF-induced pulmonary hypertension is in large part mediated through $\mathrm{TxA}_{2}$ (35). Because these derangements resemble those produced by endotoxemia, the intravascular release and actions of PAF have been studied and found to be significant in a guinea pig model of Salmonella endotoxemia (17), and in Escherichia coli endotoxemia models in sheep $(18,34)$ and rats $(19,20)$.

GBS sepsis shares much of the pathophysiology of endotoxemia. As some of its effects are mediated by cyclooxygenase and lipoxygenase products $(14,21-23)$, in animal models pharmacologic blockade of either eicosanoid significantly attenuates the pathophysiologic abnormalities $(5-9,24)$ and decreases mortality (25) in this condition.

Thus, we hypothesized that PAF is released during group B streptococcal sepsis, and may be directly or indirectly responsible for some of the pathophysiologic findings, particularly pulmonary hypertension.

\section{MATERIALS AND METHODS}

Animal Preparation. Twenty-two piglets (1-14 d old; $1.4-4.5$ $\mathrm{kg}$ ) obtained from a commercial breeder, were anesthetized with $\sim 65 \%$ nitrous oxide/ $35 \%$ oxygen $/ 1.5-4 \%$ halothane, and intravenous access established via an ear or antecubital vein. Intravenous atropine $(0.1 \mathrm{mg})$ and pancuronium $(0.1 \mathrm{mg} / \mathrm{kg})$ were followed by endotracheal intubation. The gas mixture was delivered with a Harvard (South Natick, MA) ventilator $(10 \mathrm{~mL} / \mathrm{kg}$, 30 breaths $/ \mathrm{min}$ ). The halothane content was reduced to $0.5-$ $1.0 \%$ and end-expiratory pressure was $1-3 \mathrm{~cm} \mathrm{H}_{2} \mathrm{O}$. A catheter was advanced into the aorta from a common carotid artery. Additional catheters were advanced from the ipsilateral jugular veins into the right heart and pulmonary artery. Aortic, pulmonary arterial, and proximal airway pressures were monitored via Gould P23ID pressure transducers (Gould Inc., Oxnard, CA), 
and recorded continuously (Gilson 5/6H multichannel recorder, Gilson Medical Electronics, Middleton, WI). Temperature was monitored with a rectal probe, and controlled with a heating pad and plastic wrap. During the experimental protocol, lasting $4 \mathrm{~h}$, further doses of pancuronium were given if it became necessary to abolish interference of spontaneous respirations with hemodynamic monitoring. An intravenous infusion of Ringer's lactate, with $5 \%$ dextrose, was maintained throughout the experiment.

Experimental Protocols. Effect of PAF and U46619 on pulmonary and systemic arterial pressures. In six piglets, pulmonary and systemic pressor response to intravenous PAF (gift of Dr. Bernard Arnoux, INSERM, Paris, France), and the TxA $\mathrm{A}_{2}$ (endoperoxide) analogue, U46619 (Upjohn, Kalamazoo, MI) was assessed. In addition, we determined the ability of one dose of putative antagonists of PAF (SRI 63072 and SRI 63441) or TxA (SQ 29548) to alter the effect of the above exogenous agonists. The PAF antagonists SRI 63072 (26) and SRI 63441 (27) were gifts of Dr. Dean Handley, Sandoz Research Institute, E. Hanover, NJ. SQ 29548 (28) was a gift of Dr. Martin Ogletree, Squibb Institute, Princeton, NJ. Before use, stock solutions of PAF (1.0 $\mathrm{mM}$ in $80 \%$ ethanol) were diluted with normal saline in a polypropylene tube to $1.8 \mu \mathrm{M}$. Frozen stock saline solutions of $\mathrm{U} 46619(10 \mu \mathrm{M})$ were thawed before use. SRI 63072 was dissolved in distilled water $(3 \mathrm{mg} / \mathrm{mL})$ immediately before use; SRI $63441(1 \mathrm{mg} / \mathrm{mL}$ in distilled water) was kept frozen, and aliquots thawed prior to use; a $1 \mathrm{~mL} / \mathrm{kg}$ dose of each of these solutions was used in the experiments. Each dose of SQ $29548(1.5 \mathrm{mg} /$ $\mathrm{mL}$ in $15 \%$ ethanol and $2 \%$ calcium carbonate) was $0.75 \mathrm{mg} /$ $\mathrm{kg}$. All stock solutions were kept at $-20^{\circ} \mathrm{C}$; each dose was injected as a bolus over $15 \mathrm{~s}$.

In this protocol, a dose of PAF $(0.5 \mathrm{nmol} / \mathrm{kg})$ followed $20 \mathrm{~min}$ later by $U 46619(1 \mathrm{nmol} / \mathrm{kg})$, were administered one to three times to each piglet; the 20 -min intervals between injections insured return to baseline of $\mathrm{P}_{\mathrm{PA}}$. Either PAF antagonist (SRI $63072, n=4$ and SRI $63441, n=2$ ) or the thromboxane antagonist $(n=6)$ were then given, and the response to PAF and U46619 again measured (only the results from first doses after the antagonists are reported). Peak mean $\mathrm{P}_{\mathrm{PA}}$ was used as the measured parameter, because the dose of PAF used produces only a small, transient decrease in cardiac output in the piglet (Pinheiro JMB, unpublished observations).

Effect of GBS. GBS type Ia-c (strain obtained from the YaleNew Haven Hospital Microbiology Laboratory, clinical isolate from a neonate) were incubated for $24 \mathrm{~h}$ on sheep blood agar, at $37^{\circ} \mathrm{C}$. The bacterial colonies were suspended in sterile lactated Ringer's with $5 \%$ glucose, centrifuged at $4 \times g, 3^{\circ} \mathrm{C}$ for $30 \mathrm{~min}$, and the bacterial pellet resuspended in Ringer's; bacterial concentration was adjusted to $2 \times 10^{9} / \mathrm{mL}$, using a Beckman DU-2 spectrophotometer (Beckman Instruments Inc., Fullerton, CA) and a standard curve of bacterial colony-forming units versus optical density.

The following five experimental protocols were followed to determine the effect of GBS (Fig. 3).

Control $(n=3)$. Animals were pretreated with the thromboxane antagonist vehicle $(0.75 \mathrm{~mL} / \mathrm{kg}$ of $15 \%$ ethanol in calcium carbonate) and then $3 \mathrm{~mL} / \mathrm{kg}$ of lactated Ringer's with $5 \%$ dextrose that was processed through sterile sheep blood agar plates was infused intravenously over $1 \mathrm{~h}$.

$G B S(n=5)$. Animals received GBS suspension (see above) for one hour $\left(1 \times 10^{8}\right.$ bacteria $/ \mathrm{kg} / \mathrm{min}$, or a total of $6 \times 10^{9}$ bacteria $/ \mathrm{kg}$ ). Delivery of the suspension was stopped and the animals followed for an additional $3 \mathrm{~h}$.

$P A F$ antagonists $(n=6)$. Animals were pretreated with either SRI $63072(3 \mathrm{mg} / \mathrm{kg}, n=3)$ or SRI $63441(1 \mathrm{mg} / \mathrm{kg}, n=3)$ and then GBS was administered as discussed previously. The effect of either antagonist was similar and data are combined for clarity.

$\mathrm{TXA}_{2}$ antagonist $(n=4)$. Animals were pretreated with SQ $29548(0.75 \mathrm{mg} / \mathrm{kg})$ immediately prior to the GBS infusion (see above).
Table 1. Baseline pulmonary artery pressures before $P A F$ or U46619 boluses*

\begin{tabular}{lcc}
\hline & $\begin{array}{c}\text { PAF } \\
\text { experiments }\end{array}$ & $\begin{array}{c}\text { U46619 } \\
\text { experiments }\end{array}$ \\
\hline Untreated baseline & $20.3 \pm 2.4$ & $21.5 \pm 7.7$ \\
Post-SRI 63072 baseline & $22.5 \pm 5.2$ & $21.0 \pm 8.2$ \\
Post-SQ29548 baseline & $20.7 \pm 5.7$ & $23.0 \pm 9.8$ \\
Post-SRI 63441 baseline & $16.0 \pm 0.0$ & $21.0 \pm 0.5$ \\
\hline
\end{tabular}

$*$ Mean \pm SEM, in torr; no statistical differences between groups.

Antagonists administered after $G B S(n=4)$. Animals were given SRI $63072(3 \mathrm{mg} / \mathrm{kg})$ before administration of GBS and again at 10-12 min after initiation of the GBS infusion. Ten min later SQ $29548(0.75 \mathrm{mg} / \mathrm{kg})$ was given, i.e. $20 \mathrm{~min}$ into the GBS infusion.

Measurements of airways and vascular pressures and arterial blood gases were made at baseline and 15,30,60, 120,180, and 240 min during GBS (or control) infusion. Additional measurements were made hourly for $3 \mathrm{~h}$ after cessation of GBS infusion. Cardiac output determinations were made at baseline, $15 \mathrm{~min}$ during GBS and then $1 \mathrm{~h}$ after cessation of GBS. Cardiac output was determined from indicator dilution outflow curves using ${ }^{3} \mathrm{H}$ benzoyl-phenylalanyl-alanyl-proline, a synthetic substrate for angiotensin-converting enzyme and discontinuous fraction collecting (29).

Data analysis. Data were analyzed using analysis of variance for repeated measures; when significant statistical differences ( $p$ $<0.05$ ) were present, means between groups were compared using unpaired Student's $t$ test. Results are presented as mean \pm SEM.

\section{RESULTS}

Effect of PAF and U46619 on pulmonary artery pressure in anesthetized piglet. Baseline $\mathrm{P}_{\mathrm{PA}}$ were normal and comparable in all groups (Table 1). Injection of PAF produced a rapid and large increase in $\mathrm{P}_{\mathrm{PA}}$ (see Fig. $1 E$ ) and a transient slight decrease in systemic arterial blood pressure. At the peak of the $\mathrm{P}_{\mathrm{PA}_{\mathrm{A}}}$ pressor response (approximately $1 \mathrm{~min}$ ), systemic arterial blood pressure had returned to or exceeded control and in two pigs studied, there was only a slight decrease in cardiac output (data not shown). A total of 15-20 min after the peak response, $\mathrm{P}_{\mathrm{PA}}$ had returned to baseline. Injection of U46619 (Fig. 1A) produced a similar effect, with the exception that there was only a mild, transient systemic hypertension, without initial hypotension.

Mean values of percent change in maximal $\mathrm{P}_{\mathrm{PA}}$ response to PAF or U46619 are shown in Figures 2 and 3, respectively. Each agent increased $\mathrm{P}_{\mathrm{PA}}$ by approximately $160 \%$. SQ 29548 partially reduced the effect of PAF (Figs. $1 F$ and 2 ) and completely abolished the effect of U46619 (Figs. $1 B$ and 3) on $\mathrm{P}_{\mathrm{PA}_{\mathrm{A}} \text {. At the }}$ dosages administered, SRI 63072 attenuated the $\mathrm{P}_{\mathrm{PA}}$ response to PAF (Figs. $1 G$ and 2 ) but did not significantly affect the response to U46619 (Figs. 1C and 3). SRI 63441 completely abolished the increase in $\mathrm{P}_{\mathrm{PA}}$ due to PAF (Figs. $1 \mathrm{H}$ and 2) and also slightly modified the $P_{\mathrm{PA}}$ response to U46619 (Figs. $1 D$ and 3).

Effect of GBS infusion on pulmonary and systemic hemodynamics. There were no significant changes in either $\mathrm{PaO}_{2}, \mathrm{PaCO}_{2}$, or arterial $\mathrm{pH}$ with time in any of the five experimental groups. Baseline values were: $\mathrm{PaO}_{2}=211 \pm 8$ torr; $\mathrm{PaCO}_{2}=32 \pm 2$ torr; and arterial $\mathrm{pH}=7.50 \pm 0.03$.

There was no significant effect of GBS on cardiac output measured during or after infusion in any of the experimental groups. There was a slight, but significant decrease in cardiac output, $15 \mathrm{~min}$ and $2 \mathrm{~h}$ after control infusions. Cardiac output averaged $419 \pm 29 \mathrm{~mL} / \mathrm{min} / \mathrm{kg}$ before infusion of control or GBS suspensions.

Mean systemic arterial pressure was $70 \pm 3$ torr before control or GBS infusions. There was no statistically significant effects of 


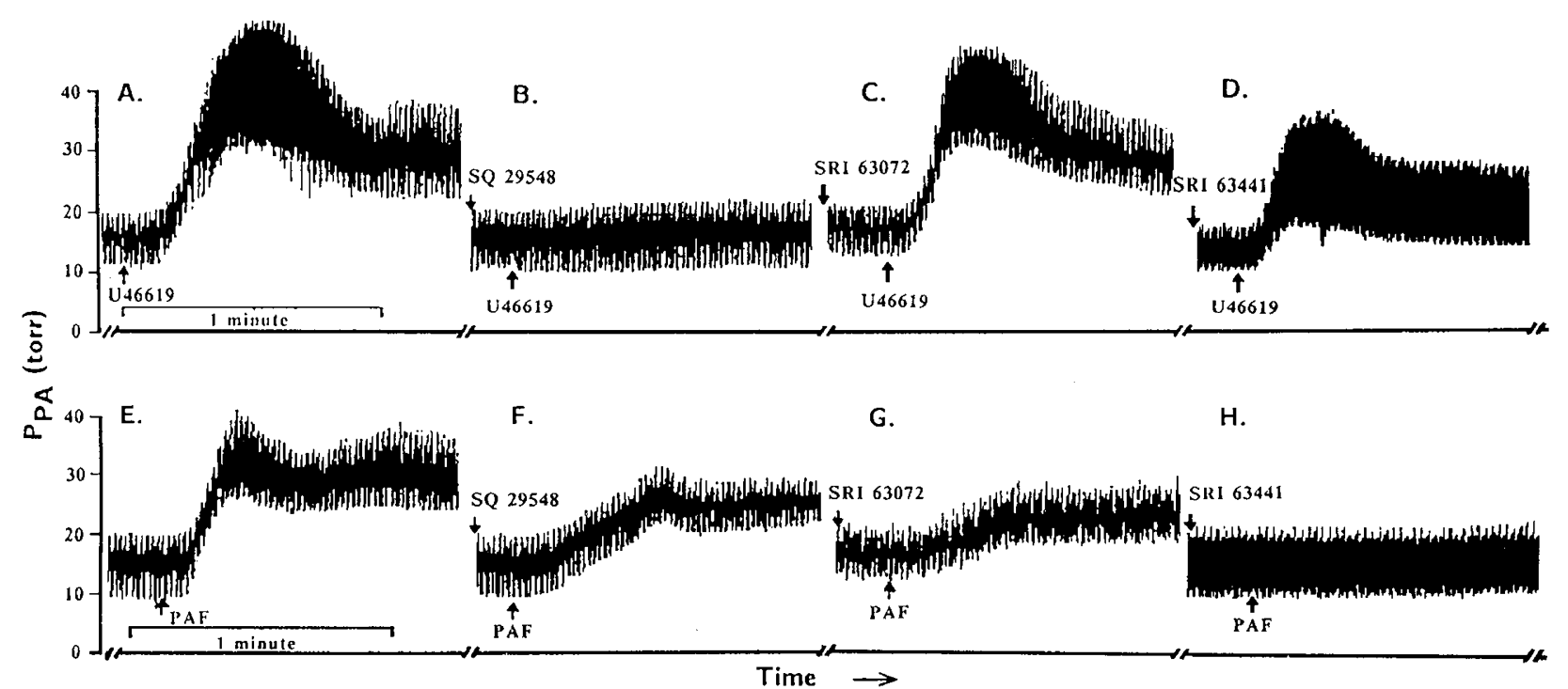

Fig. 1. $\mathrm{P}_{\mathrm{PA}}$ tracings showing response to boluses of the $\mathrm{TxA}_{2}$-mimetic $U 46619,1 \mathrm{nmol} / \mathrm{kg}$ intravenous, and its modification by the TxA antagonist SQ 29548, and PAF antagonists SRI 63072 and SRI 63441 ( $A$ to $D$ ). $E$ to $H$ demonstrate the corresponding response to PAF, $0.5 \mathrm{nmol} /$ $\mathrm{kg}$ intravenous, and its alteration by the same antagonists.

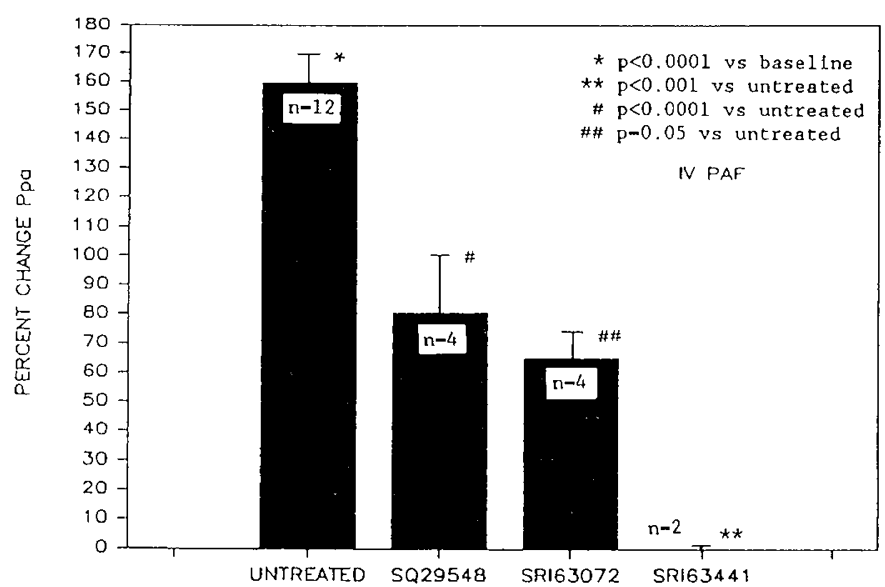

Fig. 2. Mean peak $\mathrm{P}_{\mathrm{PA}}$ response to $\mathrm{PAF}$ boluses, $0.5 \mathrm{nmol} / \mathrm{kg}$ intravenous, in piglets untreated or pretreated with $\mathrm{TxA}_{2}$ antagonist SQ 29548 or PAF antagonists. The significant ( $p<0.01$ versus baseline) increase in $\mathrm{P}_{\mathrm{PA}}$ with PAF alone was attenuated by SRI $63072(p<0.01$ versus untreated) and SQ29548 $(p=0.05)$, and abolished by SRI $63441(p<$ $0.01)$.

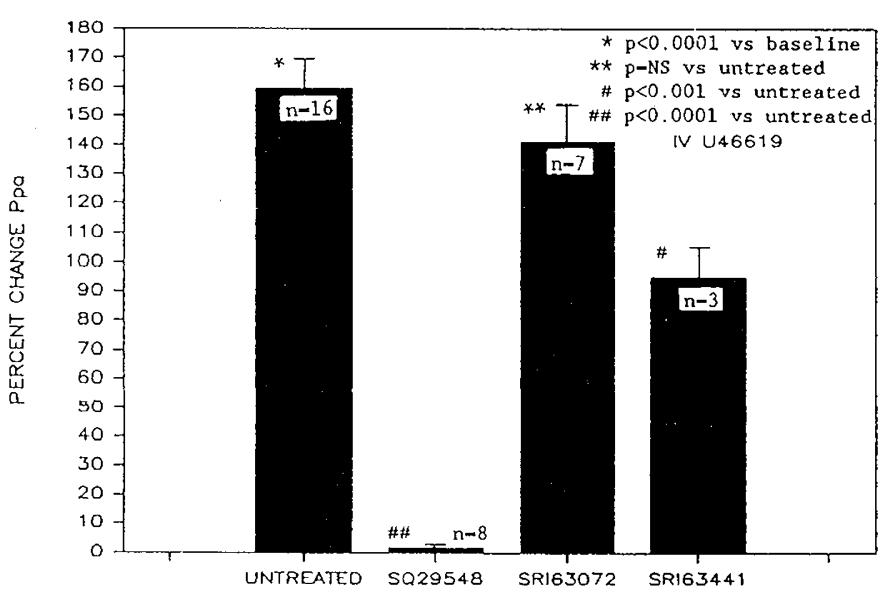

Fig. 3. Mean peak $P_{P A}$ response to $U 46619$ boluses, $1 \mathrm{nmol} / \mathrm{kg}$ intravenous, in piglets untreated, or pretreated with $\mathrm{TXA}_{2}$ antagonist SQ 29548 or PAF antagonists. The increase in $\mathrm{P}_{\mathrm{PA}_{\mathrm{A}}}(p<0.01$ versus baseline) by U46619 alone was attenuated by SRI 63441 ( $p=0.01$ versus untreated), and abolished by SQ29548 $(p<0.01)$.

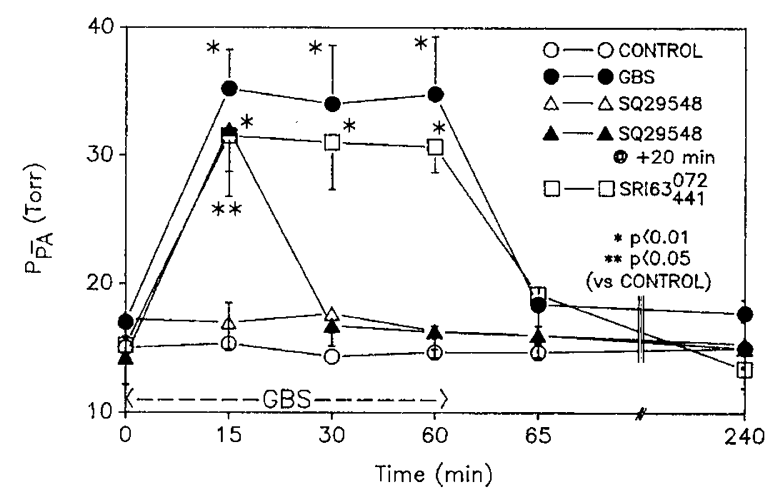

Fig. 4. Mean pulmonary artery pressure changes in each group during the study protocol. $\mathrm{P}_{\mathrm{PA}}$ increased throughout the GBS infusion; PAF antagonists did not prevent (SRI63072/441) or reverse (group SQ29548 at $+20 \mathrm{~min}$ ) such increase. SQ29548 abolished (SQ29548) and reversed (SQ29548 at $+20 \mathrm{~min}$ ) the pulmonary hypertension. ${ }^{*} p<0.01$ versus control; ** $p<0.05$.

either control or GBS infusions on mean systemic arterial pressure in untreated or treated groups.

In Figure 4, mean values of $\mathrm{P}_{\mathrm{PA}}$ are shown for all five groups. Infusion of GBS led to a prompt and sustained increase in $P_{P A}$. $P_{P A}$ returned to control values within $5 \mathrm{~min}$ of discontinuation of the GBS infusion. Pretreatment of the animals with the SQ 29548 completely inhibited the $P_{P_{A}}$ effect of GBS. In contrast, pretreatment with either SRI 63072 or SRI 63441 did not significantly affect the rise in $\mathrm{P}_{\mathrm{PA}}$ during GBS infusion. Administration of SRI 63072 during the pulmonary hypertension associated with GBS was without any effect on $\mathrm{P}_{\mathrm{PA}}$; however, injection of $\mathrm{SQ}$ 29548 promptly reversed the GBS-induced pulmonary hypertension to pre-GBS values of $P_{P_{A}}$.

\section{DISCUSSION}

Our objective in this study was to examine a possible role for PAF in the pulmonary hypertension induced by GBS in the piglet model. Given that PAF administration causes $\mathrm{TxA}_{2}$ release from platelets and into the circulation of newborn piglets (35) and sheep (38), and that $\mathrm{TxA}_{2}$ contributes to the bronchial smooth muscle effects of PAF (34), and probably to the newborn lamb's pulmonary vascular response to GBS (33), it was important to evaluate the contribution of $\mathrm{TxA}_{2}$ to a possible effect of 
PAF. A pharmacologic approach, using specific receptor antagonists, allowed us to assess the contributions of each of these circulating mediators to the pulmonary hypertension.

The use of $P_{P A}$ as a marker for the early effects of these mediators in this piglet model is justified as $P_{P_{A}}$ probably reflects pulmonary vascular resistance (cardiac output and systemic arterial pressure are not decreased in either the pharmacologic or GBS infusion experiments); further, we hope to have eliminated the component of hypoxic pulmonary vasoconstriction by maintaining the animals in a mild hyperoxic state throughout the experiments.

Prior work using models of GBS infusion had found contributions of $\mathrm{TxA}_{2}$ and leukotrienes to the early pulmonary hypertension in GBS sepsis $(5,7,11)$. There is now evidence that in the newborn piglet PAF administration causes pulmonary hypertension, which is to a large extent $\mathrm{TxA}_{2}$ mediated (35). Untested was the possibility that PAF release by GBS might activate the cyclooxygenase and lipoxygenase pathways.

Using $\mathrm{P}_{\mathrm{PA}}$ and its modification by the receptor antagonists as an endogenous bioassay for the presence of circulating PAF or $\mathrm{TxA}_{2}$, we found no evidence to support a role for PAF in producing the pulmonary hypertension in this model of GBS sepsis. Specifically, the PAF antagonists neither prevented nor reversed the pulmonary hypertension after GBS (Fig. 4); furthermore, the $\mathrm{P}_{\mathrm{PA}_{\mathrm{A}}}$ elevation was totally abolished by a TxA $\mathrm{A}_{2}$ antagonist, which, in our preliminary experiments, only attenuated the pulmonary hypertension caused by exogenous PAF. The latter finding favors $\mathrm{TxA}_{2}$ as being solely responsible for the early pulmonary hypertension in this model. This contention is strengthened by the fact that established pulmonary hypertension was rapidly reversed in toto by the administration of a $\mathrm{TxA}_{2}$ antagonist. Accordingly, our study supports the original observations of Sandberg et al. (33), using different methods.

Published work on the role of PAF in endotoxemia, although scant, supports the involvement of this mediator in the early phase of the pulmonary vascular response, whether in causing systemic hypotension $(19,20)$, or pulmonary hypertension and hypoxemia $(18,34)$. Our data suggest that PAF is not a pivotal mediator of the pulmonary hypertension associated with GBS in neonatal pigs.

Obvious differences in our model, compared to those cited above, include the use of GBS, neonatal pigs, and nonhypoxic conditions; these differences might underlie the insignificant role of PAF in our experiments. However, the pathophysiology of GBS and gram-negative septicemia is quite comparable (3-10). PAF is a ubiquitous molecule, and it has been found in the lungs of human fetuses (30) and neonates (31); one would expect it to have similar functions in piglets as in other mammals. Finally it is unclear whether hypoxemia or tissue hypoxia are necessary for PAF release in the models studied.

If endotoxemia results in enough cell membrane disturbance to activate phospholipase $A_{2}$, one would expect release of etherlinked glycerylphosphocholines [PAF precursors (22)] from the membrane. Some of the PAF thus formed can reach the circulation, where it is a very potent activator of leukocytes, platelets, and endothelial cells (32); however, in sheep, the pulmonary hypertensive, capillary leak, and decreased lung dynamic compliance responses to PAF are independent of platelets and neutrophils (38). PAF is also rapidly inactivated by plasma acetylhydrolase, into biologically inactive lyso-PAF. It is conceivable that rapid inactivation of small amounts of PAF released into the circulation will annul its effects. Thus, one can speculate that significant tissue injury may be necessary to produce pathophysiologically relevant quantities of circulating PAF, which would then amplify multiple mechanisms leading to lung dysfunction and injury. Our data show that the action of circulating PAF is not necessary to produce the early phase pulmonary vascular response.

An important consideration is a possible endothelial-dependent pulmonary vasodilatory effect of PAF. This has been demonstrated only in preconstricted rat pulmonary arteries, at low doses of PAF $(36,37)$; at higher doses or with normal baseline pulmonary vascular tone, only vasoconstriction is demonstrable (37). Doses as low as $0.01 \mathrm{nmol}$ in normoxic piglets produce only increases in pulmonary vascular resistance (35). In our piglets with normal baseline pulmonary arterial pressures, pulmonary hypertension in response to PAF was not unexpected. However, it is conceivable that circulating PAF might attenuate the vasoconstrictor effects of $\mathrm{TxA}_{2}$. Our scant evidence suggests that PAF is not a vasodilator in the baseline state, as administration of the antagonists did not result in pulmonary hypertension; also, PAF antagonism did not potentiate the U46619 or GBSinduced pulmonary hypertension, suggesting that PAF did not have a significant vasodilatory function in this system.

The use of receptor antagonists of circulating mediators, previously unreported in this model, may have significant advantages over less specific cyclooxygenase and lipoxygenase inhibitors. The improved specificity of this approach should help in evaluating the contribution of each mediator to a process. It may also decrease the potential for blocking synthesis of "protective" compounds (e.g. $\mathrm{PgI}_{2}$ ), and for shunting precursors toward the formation of potentially harmful lipoxygenase metabolites. Nevertheless, the receptor specificity of PAF and $\mathrm{TxA}_{2} / \mathrm{PgH}_{2}$ receptor antagonists is technically impossible to demonstrate in systems more complex than a receptor binding assay, due to postreceptor interactions between the two mediator systems. Our pharmacologic data show preferential inhibition of exogenous agonist effects by their respective putative antagonists, as well as some decrease in response to the other agonist. This is compatible with nonspecific binding of the drug, but also explainable by postreceptor phenomena. Indeed, the finding of Bradley et al. (35) that SQ 29548 blocks the pulmonary hypertensive response to $\mathrm{PAF}$ in piglets, although the resulting rise in $\mathrm{TxB}_{2}$ was similar, implies that the primary response to PAF ( $\mathrm{TxA}_{2}$ release) was not modified by SQ 29548

In the absence of PAF measurements, conclusions regarding its unimportant role in this model can only be reached by assuming that total PAF blockade was achieved at the doses of blockers used. Support for that assumption is derived from demonstration of effectiveness at comparable doses in original studies using these drugs $(26,27)$, and from our own evidence, where PAF effect was abolished at the doses used. We avoided higher doses because of concerns with toxicity; the bipolar nature of the drugs confers them detergent properties, and we had found platelet lysis in in vitro assays.

We find no evidence for a role of PAF in this model of GBS endotoxemia, and conclude that $\mathrm{TxA}_{2}$ is solely responsible for the pulmonary hypertensive response.

Delineation of the mediator mechanisms responsible for the often severe hemodynamic abnormalities in neonatal GBS sepsis has more than academic interest. The recent development of receptor antagonists for PAF and TxA $\mathrm{A}_{2}$ brings to the horizon the age when clinical use of such drugs can modify the body's response to invasion by endotoxins. Further investigation is now necessary to better define the utility of circulating mediator blockade, as well as its possible untoward consequences.

Acknowledgments. The authors are grateful to Christine Kontnick for supplying the GBS cultures, and Dr. George Lister for encouragement and support.

\section{REFERENCES}

1. Baker CJ 1979 Group B streptococcal infections in neonates. Pediatr Rev 1:515

2. Rojas J, Larsson LE, Hellerqvist CG, Brigham KL, Gray ME, Stahlman MT 1983 Pulmonary hemodynamic and ultrastructural changes associated with group B streptococcal toxemia in adult sheep and newborn lambs. Pediatr group B streptococcal

3. Rojas $\mathrm{J}$, Green RS, Hellerqvist CG, Olegard R, Brigham KL, Stahlman MT 1981 Studies on group B beta-hemolytic streptococcus. II: effects on pulmonary hemodynamics and vascular permeability in unanesthetized sheep. Pediatr Res 15:899-904

4. Olson TA, Fischer GW, Hemming VG, O'Brien WF, Golden SM, Maybee DA 
1987 A group B Streptococcal extract reduces neutrophil counts and induces neutrophil aggregation. Pediatr Res 21:326-330

5. Rojas J, Larsson LE, Ogletree ML, Brigham KL, Stahlman MT 1983 Effects of cyclooxygenase inhibition on the response to group B streptococcal toxin in sheep. Pediatr Res 17:107-110

6. Runkle B, Goldberg RN, Streitfeld MM, Clark MR, Buron E, Setzer ES, Bancalari E 1984 Cardiovascular changes in group B streptococcal sepsis in the piglet: responses to indomethacin and relationship to prostacyclin and thromboxane A2. Pediatr Res 18:874-878

7. Hammerman C, Komar K, Abu-Khudair H 1988 Hypoxic vs septic pulmonary hypertension-selective role of thromboxane mediation. Am J Dis Child 142:319-325

8. Truog WE, Sorensen GK, Standaert TA, Redding GJ 1986 Effects of the thromboxane synthetase inhibitor, Dazmegrel (UK 38,485), on pulmonary gas exchange and hemodynamics in neonatal sepsis. Pediatr Res 20:481-486

9. Peevy KJ, Panus P, Longenecker GL, Chartrand SA, Wiseman HJ, Boerth RC, Olson RD 1986 Prostaglandin synthetase inhibition in group B Streptococcal shock: hematologic and hemodynamic effects. Pediatr Res 20:864866

10. Brigham KL, Meyrick B 1986 Endotoxin and lung injury. Am Rev Respir Dis 133:913-927

11. Goldberg RN, Suguihara C, Streitfeld MM, Bancalari A, Clark MR, Bancalar E 1986 Effects of a leukotriene antagonist on the early hemodynamic manifestations of group B streptococcal sepsis in piglets. Pediatr Res 20:1004-1008

12. Mojarad M, Cox CP, Said SI 1985 Platelet-activating factor (PAF) and acute lung injury. In: Said SI (ed) The Pulmonary Circulation and Acute Lung Injury. Futura Publishing Co., Inc., Mount Kisco, NY, pp 375-385

13. Pinckard RN 1985 Platelet activating factor. In: Kaplan AP (ed) Allergy. Churchill Livingstone, New York, pp 165-174

14. Burhop KE, VanDerZee H, Bizios R, Kaplan JE, Malik AB 1986 Pulmonary vascular response to platelet-activating factor in awake sheep and the role of cyclooxygenase metabolites. Am Rev Respir Dis 134:548-554

15. Ivanick MJ, Schreiber R, Strope GL, Wyrick SD, Piantadosi C, Bromberg PA Ranga V 1985 Platelet-activating factor (PAF) induced bronchoconstriction is associated with altered respiratory epithelial permeability in the guinea pig. Am Rev Respir Dis 131:A281(abstr)

16. Pinheiro J, Arnoux B, Pitt BR 1986 Effects of platelet-activating factor on clearance of $[(99) \mathrm{m}]$ Tc-DTPA in isolated rabbit lung in situ. Am Rev Respir Dis 133:A279(abstr)

17. Etienne A, Hecquet F, Soulard C, Spinnewyn B, Clostre F, Braquet P 1985 In vivo inhibition of plasma protein leakage and Salmonella enteritidis-induced mortality in the rat by a specific PAF-acether antagonist: BN 52021. Agents Actions 17:368-370

18. Christman BW, Lefferts PL, Snapper JR 1987 Effect of a platelet activating factor receptor antagonist (SRI 63-441) on sheep's response to endotoxin. Am Rev Respir Dis 135:A82(abstr)

19. Handley DA, Van Valen RG, Melden MK, Flury S, Lee ML, Saunders RN 1986 Inhibition and reversal of endotoxin-, aggregated IgG- and PAFinduced hypotension in the rat by SRI-63-072, a PAF receptor antagonist. Immunopharmacology 12:11-16

20. Handley DA, Van Valen RG, Tomesch JC, Melden MK, Jaffe JM, Ballard FH, Saunders RN 1987 Biological properties of the antagonist SRI 63-441 in the PAF and endotoxin models of hypotension in the rat and dog. Immunopharmacology 13:125-131
21. Vargaftig BB, Lefort J, Rotilio D 1983 Route-dependent interactions between PAF-acether and guinea-pig bronchopulmonary smooth muscle: relevance of cyclooxygenase mechanisms. In: Benveniste J, Arnoux B (eds) PlateletActivating Factor. INSERM Symposium No. 23. Elsevier Science Publishers B. V., Amsterdam, pp 307-316

22. Bonnet J, Thibaudeau D, Bessin P 1983 The roles of the lipoxygenase and cyclooxygenase pathways in PAF-acether induced bronchospasm in the guinea pig. In: Benveniste J, Arnoux B (eds) Platelet-Activating Factor. INSERM Symposium no. 23. Elsevier Science Publishers B.V., Amsterdam, pp 319-326

23. Voelkel NF, Worthen S, Reeves JT, Henson PM, Murphy RC 1982 Nonimmunological production of leukotrienes induced by platelet-activating factor Science 218:286-288

24. Rojas J, Palme C, Ogletree ML, Hellerqvist CG, Brigham KL, Stahlman MT 1984 Effects of methylprednisolone on the response to group B streptococcal toxin in sheep. Pediatr Res 18:1141-1144

25. Short BL, Miller MK, Fletcher JR 1982 Improved survival in the suckling rat model of group B streptococcal sepsis after treatment with nonsteroidal antiinflammatory drugs. Pediatrics 70:343-347

26. Handley DA, Van Valen RG, Saunders RN 1986 Vascular responses of plateletactivating factor in the Cebus apella primate and inhibitory profiles of antagonists SRI 63-072 and SRI 63-119. Immunopharmacology 12:175-182

27. Handley DA, Tomesch JC, Saunders RN 1986 Inhibition of PAF-induced systemic responses in the rat, guinea pig, dog and primate by the receptor antagonist SRI 63-441. Thromb Haemost 56:40-44

28. Ogletree ML, Harris DN, Greenberg R, Haslanger MF, Nakane M 1985 Pharmacological actions of SQ 29,548, a novel selective thromboxane antagonist. J Pharmacol Exp Ther 234:435-441

29. Pitt BR, Lister G, Davies P, Reid L 1987 Correlation of pulmonary ACE activity and capillary surface area during postnatal development. J Appl Physiol 62:2031-2041

30. Hoffman DR, Truong CT, Johnson JM 1986 The role of platelet-activating factor in human fetal lung maturation. Am J Obstet Gynecol 155:70-75

31. Stenmark KR, Eyzaguirre M, Westcott JY, Henson PM, Murphy RC 1987 Potential role of eicosanoids and PAF in the pathophysiology of bronchopulmonary dysplasia. Am Rev Respir Dis 136:770-772

32. Snyder F, Lee T-C, Blank ML, Cabot MC, Malone B, Albert DH 1983 Enzymatic pathways for platelet activating factor. In: Benveniste J, Arnoux B (eds) Platelet-Activating Factor. INSERM Symposium no. 23. Elsevier Science Publishers B.V., Amsterdam, pp 253-259

33. Sandberg K, Engelhardt B, Hellerqvist C, Sundell H 1987 Pulmonary response to group B streptococcal toxin in young lambs. J Appl Physiol 63:20242030

34. Sessler CN, Glauser FL, Davis D, Fowler III AA 1988 Effects of plateletactivating factor antagonist SRI 63-441 on endotoxemia in sheep. J Appl Physiol 65:2624-2631

35. Bradley LM, Goldstein RE, Feuerstein G, Czaja JF 1989 Circulatory effects of PAF-acether in newborn piglets. Am J Physiol 256:H205-H212

36. Gillespie MN, Bowdy BD 1986 Impact of platelet activating factor on vascular responsiveness in isolated rat lungs. J Pharmacol Exp Ther 236:396-402

37. McMurtry IF, Morris KG 1986 Platelet-activating factor causes pulmonary vasodilation in the rat. Am Rev Respir Dis 134:757-762

38. Christman BW, Lefferts PL, King GA, Snapper JR 1988 Role of circulating platelets and granulocytes in PAF-induced pulmonary dysfunction in awake sheep. J Appl Physiol 64:2033-2041 